\title{
Semantic memory is impaired in both dementia with Lewy bodies and dementia of Alzheimer's type: a comparative neuropsychological study and literature review
}

\author{
M A Lambon Ralph, J Powell, D Howard, A B Whitworth P Garrard, J R Hodges
}

Department of Experimental Psychology, University of Bristol, 8 Woodland Road, Bristol BS8 1TN, UK M A Lambon Ralph

Department of Speech, University of

Newcastle, UK

J Powell

D Howard

A B Whitworth

University

Department of

Neurology,

Addenbrooke's

Hospital, Cambridge,

UK

P Garrard

J R Hodges

MRC Cognition and Brain Sciences Unit, Cambridge, UK

J R Hodges

Correspondence to: Dr M A Lambon Ralph matt.lambon-ralph@bristol. ac.uk

Received 10 November 1999 and in final form

10 August 2000

Accepted 14 August 2000

\begin{abstract}
Objective-To test the hypothesis that semantic impairment is present in both patients with dementia with Lewy bodies (DLB) and those with dementia of Alzheimer's type (DAT).

Methods-A comprehensive battery of neuropsychological tasks designed to assess semantic memory, visuoperceptual function, verbal fluency, and recognition memory was given to groups of patients with DLB $(n=10)$, DAT $(n=10)$ matched pairwise for age and mini mental state examination (MMSE), and age matched normal controls $(n=15)$.

Results-Both DLB and DAT groups exhibited impaired performance across the range of tasks designed to assess semantic memory. Whereas patients with DAT showed equivalent comprehension of written words and picture stimuli, patients with DLB demonstrated more severe semantic deficits for pictures than words. As in previous studies, patients with DLB but not those with DAT were found to have impaired visuoperceptual functioning. Letter and category fluency were equally reduced for the patients with DLB whereas performance on letter fluency was significantly better in the DAT group. Recognition memory for faces and words was impaired in both groups.

Conclusions-Semantic impairment is not limited to patients with DAT. Patients with DLB exhibit particular problems when required to access meaning from pictures that is most likely to arise from a combination of semantic and visuoperceptual impairments.

(f Neurol Neurosurg Psychiatry 2001;70:149-156)
\end{abstract}

Keywords: dementia of Alzheimer's type; dementia with Lewy bodies; semantic memory; neuropsychology

Dementia with Lewy bodies (DLB) is now considered to be the second most common pathological cause of dementia in elderly people after dementia of Alzheimer's type (DAT). ${ }^{1}$ As many as $12 \%-26 \%$ of patients with a clinical diagnosis of Alzheimer's disease meet the neuropathological criteria for a diagnosis of DLB. $^{23}$ Various labels have been used to categorise dementia associated with Lewy bodies, including diffuse Lewy body disease (DLBD), ${ }^{4}$ senile dementia of Lewy body type
(SDLT), ${ }^{35}$ and Lewy body variant of Alzheimer's disease (LBV). ${ }^{6}$ We have adopted the term DLB as recommended by a recent consensus group ${ }^{2}$; DLB is characterised pathologically by Lewy body formation in the cerebral cortex, brain stem nuclei (substantia nigra and locus cooeruleus), and components of the basal forebrain cholinergic system. ${ }^{7}$ The clinical features of DLB include a cortical dementia with fluctuating confusion, spontaneous parkinsonism, sensitivity to neuroleptic drugs, and psychiatric manifestations of especially well formed and recurrent visual hallucinations early in the course of the disease. ${ }^{189} \mathrm{~A}$ recent SPECT study that compared the regional cerebral blood flow ( $\mathrm{rCBF}$ ) differencies between DLB and DAT found that $\mathrm{rCBF}$ was lower in the occipital lobes bilaterally but higher in the right medial temporal lobe in the DLB group than in the DAT group. ${ }^{10}$

Although DLB is now accepted as a separate clinical entity, differentiating it from DAT remains problematic especially in those cases where initial presentation of DLB is impaired cognition. ${ }^{611}$ Overlapping distributions of pathology can result in very similar clinical presentations, especially in the early stages, with memory impairment often being the earliest and most prominent feature of both types of dementia. ${ }^{12}$ This generally leads to a misdiagnosis as DAT rather than Parkinson's disease due to the predominance of cognitive changes and only mild extrapyramidal symptoms. ${ }^{12}$ Detailed neuropsychological investigation into the exact nature of the cognitive decline, therefore, may provide us with knowledge of key differentiating features of DLB.

In comparison with Alzheimer's disease relatively little is known about the neuropsychological deficits in DLB. Table 1 summarises the results from the few studies that have compared DLB and DAT performance on a range of neuropsychological assessments. The global impression from this summary is that ability in DLB is impaired across all areas of cognition. Perceptual and spatial impairments are nearly always more pronounced in DLB than DAT. This is true not only of those assessments that tap both visuoperceptual/spatial ability and praxis such as picture copying or construction tasks, but also true of purely visuoperceptual and spatial tasks such as those included in the visual object and space perception battery (VOSP) battery. ${ }^{13}$ Whereas it is clear from the extensive literature that attentional function is compromised in Alzheimer's disease, ${ }^{14}$ there is 

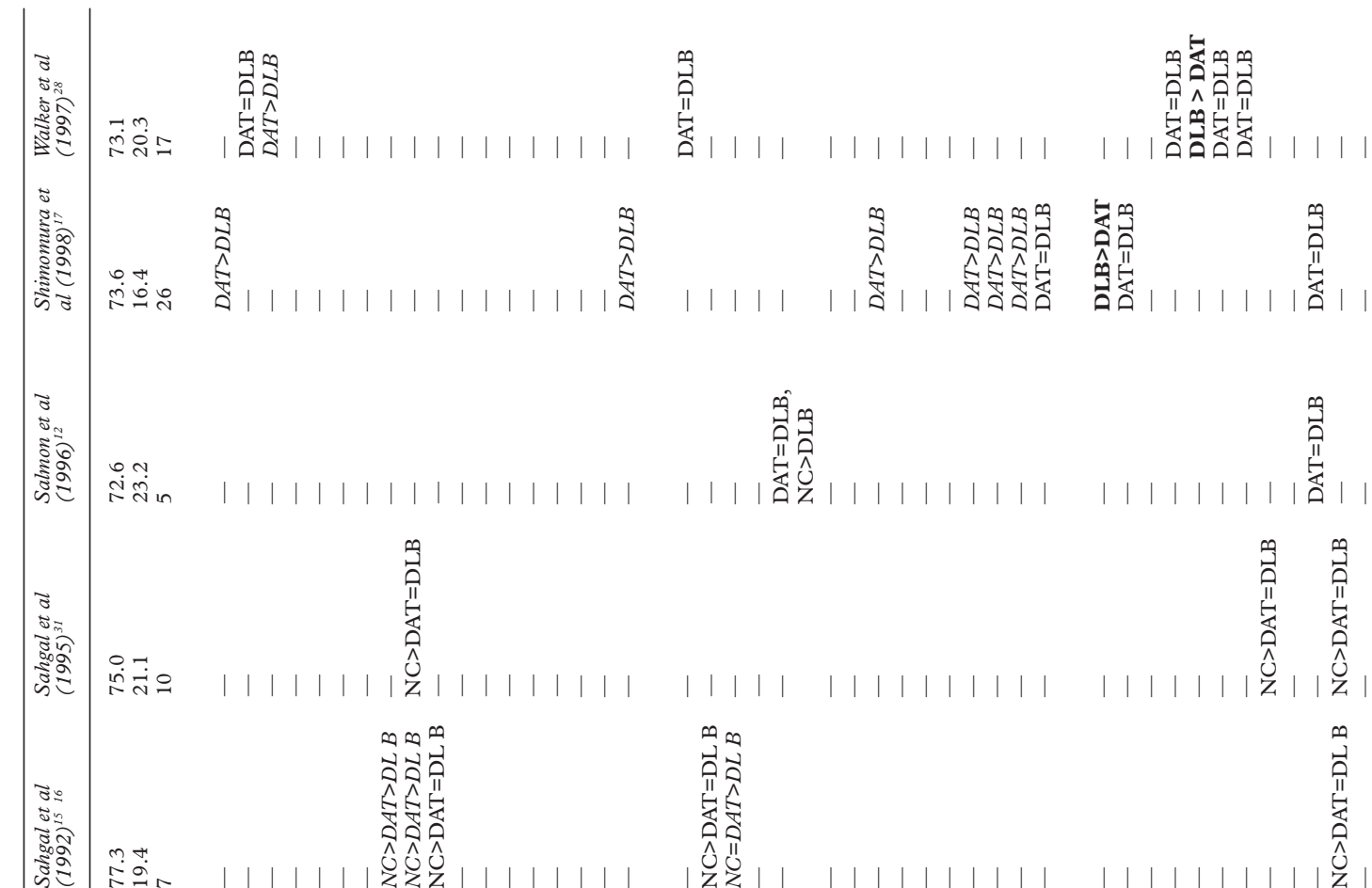

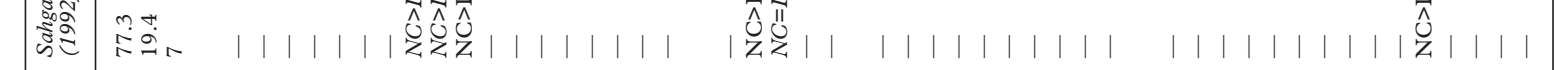

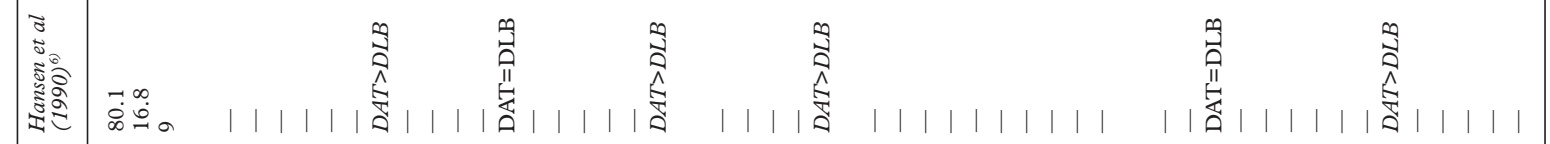

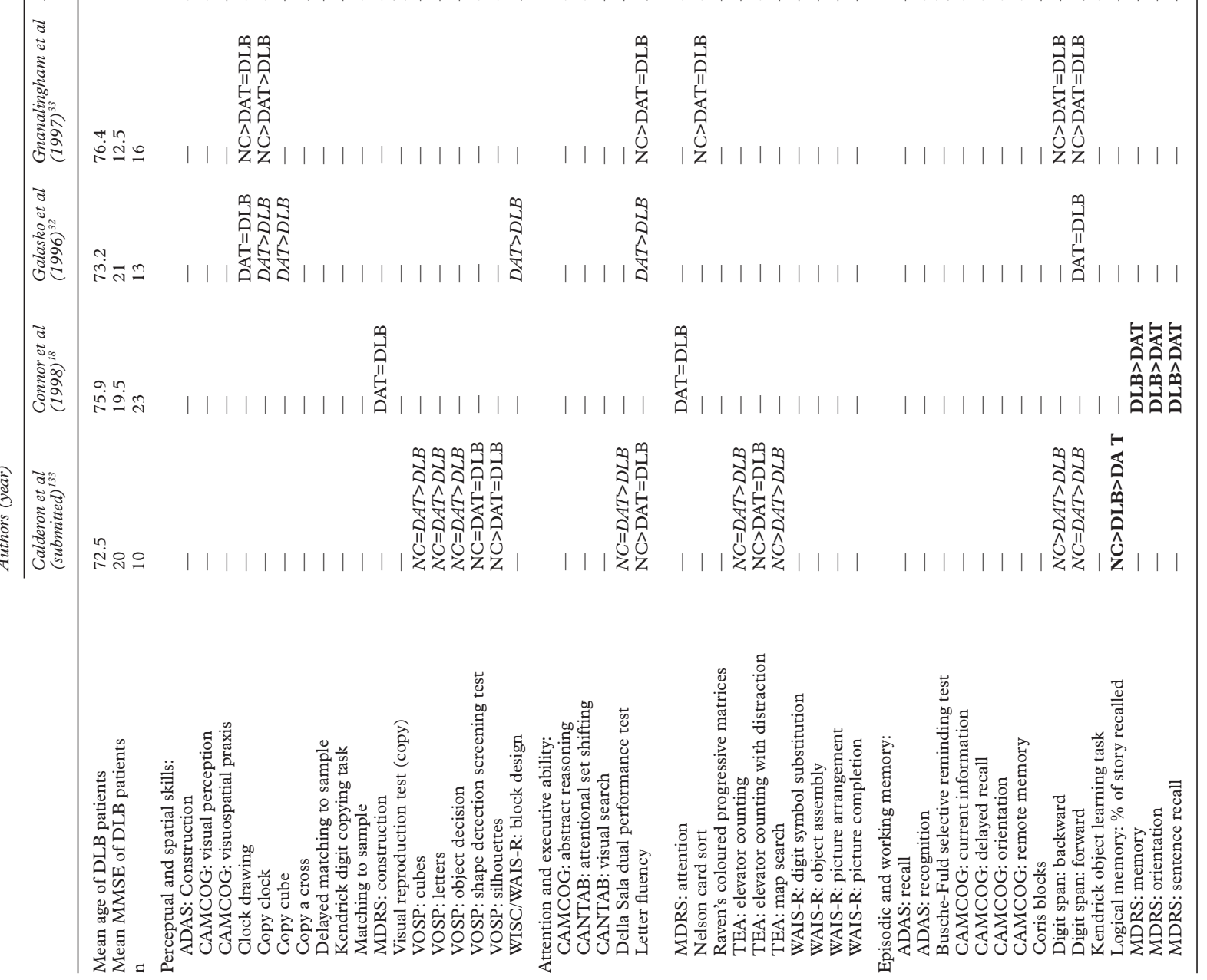




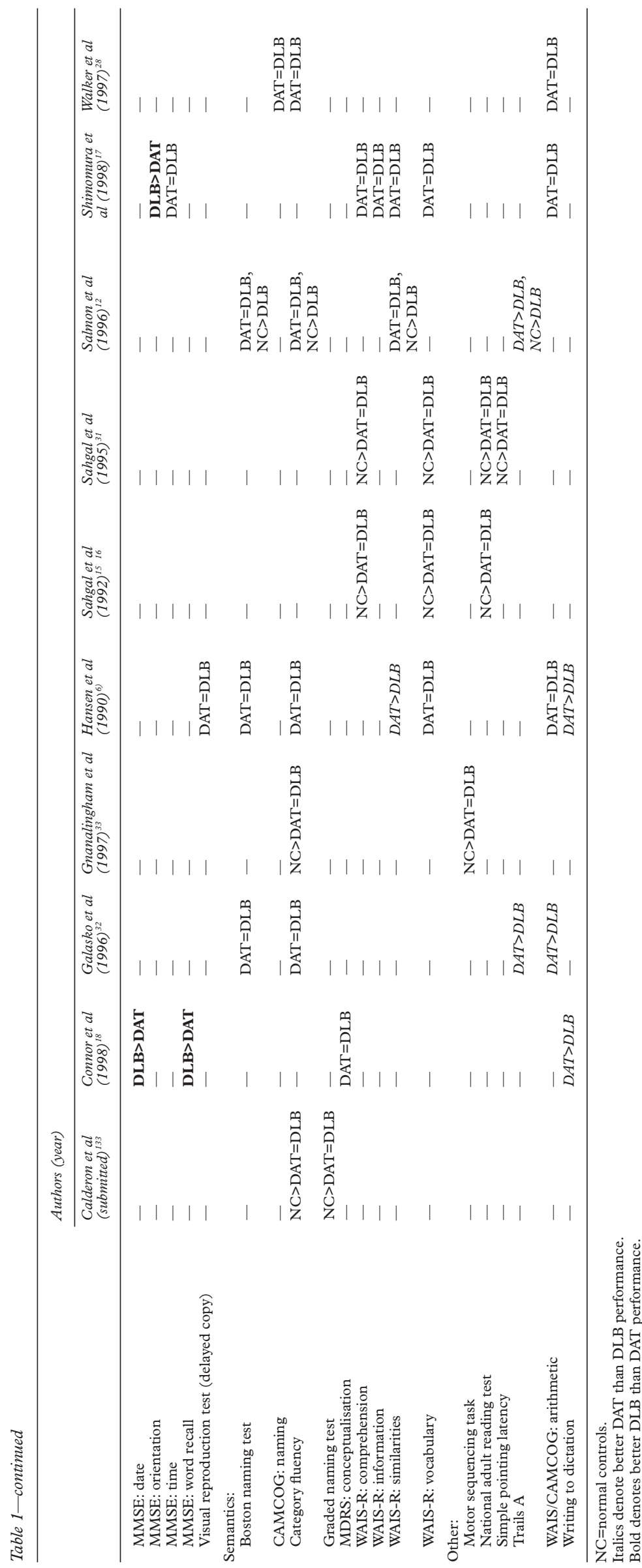

relatively little data on DLB. Calderon et $a l^{13}$ ran a series of attentional tasks with their DLB and DAT groups, and found that the attentional deficit in DLB was more pronounced than in DAT. The performance of patients with DAT fell to the same level as the patients with DLB only when selective attention was targeted in the assessment (TEA: elevator counting with distraction). Executive ability seems to be equally impaired in DLB and DAT. Three studies have highlighted greater impairment in patients with DLB. ${ }^{15-17}$ In all cases, however, the stimuli were visually presented (for example, Raven's coloured progressive matrices, WAIS-R digit symbol substitution) leaving open the possibility that the poor performance in DLB reflects a combination of impaired executive as well as visuoperceptual/spatial skills.

Episodic and working memory provide the only examples of cognitive tasks in which performance is usually found to be relatively better in DLB than in DAT. In simple working memory assessments such as digit span, there is an equivalent impairment in DLB and DAT. Although immediate recall is impaired, patients with DLB can often recall a much greater proportion of this information after a delay. One possible explanation for this difference may be that initial encoding of the to be remembered information is compromised by the pervasive attentional deficit seen in DLB, but the reduced amount of information that is successfully encoded is more likely to be recalled later. The amnestic syndrome in DAT, however, increasingly compromises recall as the delay increases. In addition two studies have found patients with DLB to be better oriented than those with DAT. ${ }^{17} 18$

Little is known about the status of semantic memory (our store of conceptual knowledge relating to objects, people, words, etc) in patients with DLB and this central component of cognition has not been the focus of any previous neuropsychological study with this patient group. Each of the studies summarised in table 1 has included some measures that require access to semantic memory within the test battery administered. These can be split into two types: measures of comprehension and of verbal output. Some of the studies have analysed the results from various subtests from the WAIS-R battery. These all require access to word meaning and to our store of conceptual knowledge - that is, semantic memory - and DLB and DAT groups showed an equivalent impairment. These results, however, have the weakness of confounding comprehension with attentional and executive function-that is, these subtests from the WAIS-R require the subjects not only to access their conceptual knowledge but then to problem solve and organise the information further. The same potential problem is true of category fluency, for which there seems to be a similar level of impairment in these two patient groups. Thus it is important to note that when Salmon et $a l^{12}$ compared the two types of fluency directly, they found that category and letter fluencies were equally reduced in DLB, unlike patients 
Table 2 Semantic assessment results for DLB, DAT, and normal control (NC) groups

\begin{tabular}{|c|c|c|c|c|c|c|}
\hline Test (maximum score) & $N C$ & $D L B$ & $D A T$ & $\begin{array}{l}\text { One way } \\
\text { ANOVA } \\
F \text { Value }\end{array}$ & $p$ Value & $\begin{array}{l}\text { Significant post } \\
\text { hoc differences }\end{array}$ \\
\hline Age (y) & $71.5(3.5)$ & $76.4(9.1)$ & $71.7(5.1)$ & 2.3 & 0.12 & N/A \\
\hline MMSE & $28.8(1.1)$ & $18.8(5.2)$ & $20.6(3.0)$ & 34.3 & $<0.001$ & $\mathrm{NC}>\mathrm{DLB}=\mathrm{DAT}$ \\
\hline \multicolumn{7}{|l|}{ Semantic assessments: } \\
\hline Graded naming test (30) & $25.1(2.3)$ & $9.4(3.0)$ & $14.2(6.1)$ & 31.5 & $<0.001$ & $\mathrm{NC}>\mathrm{DAT}>\mathrm{DLB}$ \\
\hline 64 Item picture naming $(64)$ & $62.1(1.9)$ & $56.3(4.3)$ & $56.7(3.8)$ & 12.1 & $<0.001$ & $\mathrm{NC}>\mathrm{DLB}=\mathrm{DAT}$ \\
\hline Spoken word to picture matching (64) & $63.8(0.4)$ & $59.3(3.0)$ & $62.6(1.5)$ & 19.2 & $<0.001$ & $\mathrm{NC}=\mathrm{DAT}>\mathrm{DLB}$ \\
\hline \multicolumn{7}{|l|}{ Camel and cactus test: } \\
\hline Pictures (64) & $58.4(3.4)$ & $41.4(10.5)$ & $54.8(4.5)$ & See text & & \\
\hline Words (64) & $60.0(2.0)$ & $48.2(6.8)$ & $51.8(4.2)$ & & & \\
\hline \multicolumn{7}{|l|}{ Category sorting pictures: } \\
\hline Level 1 (proportion correct) & $0.99(0.03)$ & $0.97(0.05)$ & $0.97(0.06)$ & See text & & \\
\hline Level 2 (proportion correct) & $0.97(0.02)$ & $0.90(0.08)$ & $0.96(0.03)$ & & & \\
\hline Level 3 (proportion correct) & $0.93(0.03)$ & $0.85(0.06)$ & $0.92(0.03)$ & & & \\
\hline \multicolumn{7}{|l|}{ Category sorting words: } \\
\hline Level 1 (proportion correct) & $1.0(0)$ & $0.97(0.05)$ & $0.99(0.03)$ & See text & & \\
\hline Level 2 (proportion correct) & $0.96(0.03)$ & $0.85(0.09)$ & $0.96(0.04)$ & & & \\
\hline Level 3 (proportion correct) & $0.93(0.03)$ & $0.85(0.05)$ & $0.92(0.03)$ & & & \\
\hline Category fluency (mean number/category) & $15.0(2.3)$ & $6.2(2.5)$ & $6.4(2.3)$ & See text & & \\
\hline
\end{tabular}

Results are reported as mean (SD).

$\star=$ Denotes no significant difference; > denotes significantly higher score.

$\mathrm{N} / \mathrm{A}=$ Not applicable.

with DAT, where category fluency was lower than letter fluency. Category fluency is assumed to rely more heavily on semantic memory whereas the requirements for working memory and executive ability seem to be the same for the two tasks. These results would seem, therefore, to point to a semantic deficit over and above any other concurrent deficits in $\mathrm{DAT}^{19}$ whereas the poor fluency in DLB might just reflect their poor attention, executive abilities, and working memory. Confrontational naming, however, provides a neuropsychological measure that requires automatic, online access to meaning (the meaning of a picture must be retrieved before naming can proceed) with little or no requirement for attention and executive abilities. Where picture naming has been assessed using either the Boston naming test or the graded naming test, patients with DLB or DAT have exhibited a similar level of impairment, and as there is no evidence for a postsemantic speech production deficit in either DAT or DLB, this result suggests that both patient groups have impaired semantic memory.

The aim of this study was to compare matched groups of patients with DLB and DAT using a comprehensive battery of neuropsychological tests designed specifically to evaluate semantic memory. The collection of semantic memory tasks varies in the reliance on other cognitive domains such as attention and executive function. In respect of the clear evidence for visuoperceptual/spatial deficits in DLB, two of the tasks include written and pictorial conditions. It is possible that the patients with DLB might perform better on tasks that assess semantic memory using word stimuli than those relying on pictorial input due to visuoperceptual difficulties in addition to a potential semantic memory deficit. The patients with DAT, who typically have little or no visuoperceptual impairment in the early course of the disease, should perform equally on tests of comprehension regardless of the modality of input.

\section{Methods}

SUBJECT GROUPS

Three subject groups participated in this study. Ten patients with DLB, 10 with DAT, and 15 normal controls. Consultants from Bensham Hospital, Gateshead and Newcastle General Hospital referred patients with a current diagnosis of DLB according to the consensus criteria. ${ }^{2}$ Patients with DAT were identified through the Memory and Cognitive Disorders Clinic at Addenbrooke's Hospital, Cambridge. The diagnosis of DAT was made according to the criteria developed by the National Institute of Neurology and Communication Disorders and Stroke (NINCDS) and the Alzheimer's Disease and Related Disorders Association (ADRDA). ${ }^{20}$ Due to the amount and type of assessment in this study, patients were required to have a mini mental state examination (MMSE) score of no less than 10 and testing was completed over several short sessions to minimise fatigue. Patients with a history of known or suspected transient cerebral ischaemic event or stroke, head injury, or major medical illness were excluded, as were those with major depression. The control subjects were selected from the MRC Cognition and Brain Sciences Unit volunteer subject panel.

Patients with DLB and those with DAT were matched as closely as possible by MMSE and age. Control subjects were matched as closely as possible for age. An analysis of variance (ANOVA) confirmed that there were no significant differences in age across the three groups $(F(2,37)=2.3, \mathrm{p}=0.12)$. There was a significant difference in MMSE across the groups $(F(2,37)=37.3, \mathrm{p}<0.001)$. Post hoc analyses (Tukey's HSD ${ }^{21}$ ) confirmed that the patients with DLB and those with DAT scored significantly below the normal controls but were not different from each other (for mean age and MMSE of each group, see table 2).

ASSESSMENT OF SEMANTIC MEMORY

The status of conceptual memory was investigated using a comprehensive battery of neuropsychological tasks including measures of 
verbal output and comprehension of written words and pictured concepts. The specific tasks included were:

\section{(1) Graded naming test ${ }^{22}$}

This is a stringent 30 item picture naming test in which the target items become increasingly unfamiliar.

\section{(2) Semantic battery}

This is a collection of tests that use the same set of stimulus items to assess conceptual knowledge systematically across different input and output modalities. It contains 64 items selected from the corpus of line drawings by Snodgrass and Vanderwart, ${ }^{23}$ representing three categories of living things (animals, birds, and fruit) and three categories of artefacts (household items, tools, and vehicles). The following subtests from the semantic battery were administered:

(a) Picture naming.

(b) Spoken word to picture matching using picture arrays containing the target plus nine within category foils.

(c) The camel and cactus test assesses knowledge of semantic association and is based on the principle of the pyramids and palm trees test. ${ }^{24}$ Subjects are asked to choose one of four same category items that has an associative relation with the target. For example, in one of the trials the subject is asked to match a camel to one of four types of vegetation: cactus (the target), tree, sunflower, or rose. The target items for this test were the same 64 concepts as those included in the rest of the semantic battery. The assessment is administered in two forms: in one, all items (targets and response choices) were presented as pictures; in the other form, all stimuli were written words.

(d) The category sorting test investigates conceptual knowledge at three levels. Subjects are required to sort the 64 concepts into living or non-living domains (level 1), into the appropriate categories (level 2), and by specific attributes (for example, by the real life size of an object: level 3 ). The stimuli for sorting are presented either as written words or pictures.

(e) Category fluency in which the subject is asked to produce as many exemplars as possible in 1 minute for each of the six categories.

OTHER NEUROPSYCHOLOGICAL ASSESSMENTS The following tasks were also administered:

\section{(1) Letter fluency}

In this task subjects are asked to generate as many words as possible beginning with the letters $\mathrm{F}, \mathrm{A}$, and $\mathrm{S}$ within 1 minute. As noted in the introduction above, letter fluency can be used as a direct contrast to category fluency.

(2) Visual object and space perception battery $(\text { VOSP })^{25}$

Three subtests were administered:

(a) Shape detection screening test-this assessment establishes whether or not the subject has adequate shape discrimination skills.

(b) Incomplete letters - this subtest requires the subject to identify a series of letters that have been perceptually degraded by removing up to $70 \%$ of the target letter.

(c) Object decision-the subject is asked to select which of four silhouettes is of a real object (the other three are nonsense silhouette forms).

\section{(3) Short recognition memory test ${ }^{26}$}

The two versions of this task assess recognition memory for 25 faces and 25 words.

(4) New adult reading test $(N A R T)^{27}$

this test provides an estimate of premorbid IQ by requiring the subject to read aloud a list of increasing rare words with unique pronunciations.

\section{Results}

ASSESSMENT OF SEMANTIC MEMORY

A summary of the semantic assessments for each group is shown in table 2, along with a series of one way ANOVA and subsequent post hoc analyses (Tukey's HSD), where appropriate. (Fifteen separate ANOVAs were used to test the differences between the three subject groups. Where there was an effect of group, the effect was highly significant in all but two tests $(p<0.001)$, and they survive correction for multiple comparisons.) The patients with DLB demonstrated impaired performance across all the administered assessments (their scores were significantly worse than normal controls). On the graded naming test and the 64 item picture naming, both DAT and DLB groups performed worse than the control subjects. The DLB group was also significantly impaired on the simple spoken word to picture matching task. Given that the three assessments require little in the way of attentional and executive abilities, these results support the notion of a semantic impairment in both DAT and DLB.

Results from the camel and cactus test (fig 1) were first analysed using a $3 \times 2$ split plot ANOVA. This disclosed an effect of group $(F(2,30)=23.8, \mathrm{p}<0.001)$ and Tukey's HSD post hoc analysis showed that there were significant differences between all three groups in the order NC $>$ DAT $>$ DLB. There was also a main effect of modality $(F(1,30)=4.9, \mathrm{p}=0.04)$ and a significant interaction $(F(2,30)=8.6$, $\mathrm{p}=0.001$. Repeated measures post hoc $t$ tests

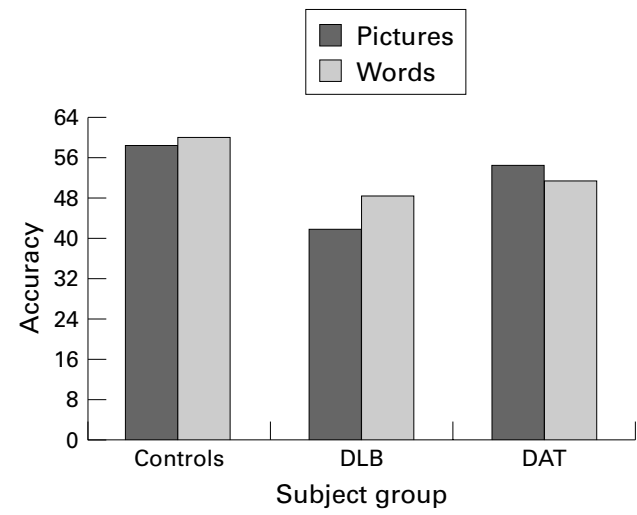

Figure 1 Camel and cactus test results for dementia of Lewy body and Alzheimer's type, and normal controls. 


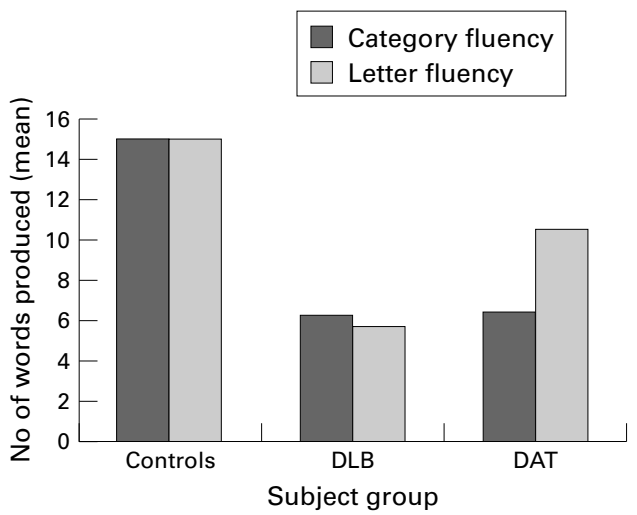

Figure 2 Category and letter fluency for dementia of Lewy body and Alzheimer's type, and normal controls.

showed that there was no significant difference between picture and word performance for the normal controls or the DAT group, but that the patients with DLB were significantly worse at the picture than word version $(t=4.4$, $\mathrm{p}=0.002)$. This modality effect shows that, although both groups of patients perform poorly on semantic memory tests, patients with DLB have a specific difficulty with pictures.

Table 2 shows that the performance of the patient groups on the sorting task was not that dissimilar to the control subjects with accuracy graded in terms of the level of sorting - best on level 1 (sorting at the superordinate level) and worst on level 3 (sorting by specific semantic attributes). Picture and word sorting data were analysed using a $3 \times 3 \times 2$ split plot ANOVA. This confirmed significant main effects of group $(F(2,30)=17.9, \mathrm{p}<0.001)$. Post hoc analyses (Tukey's HSD) showed that the patients with DLB performed slightly but significantly lower (overall $90 \%$ correct) than either the DAT (95\%) or normal control groups (96\%). There was also an effect of level of sorting $(F(2,60)=47.9, \mathrm{p}<0.001)$ but no main effect of modality $(F<1)$. There was also a significant interaction between level and group $(F(4,60)=4.2, \mathrm{p}=0.005)$. No other interactions reached significance.

Figure 2 shows the direct comparison between category and letter fluency for the three subject groups (see table 3 for the specific letter fluency results). A $3 \times 2$ split plot ANOVA disclosed a main effect of group $(F(2,32)=62.7, \mathrm{p}<0.001)$, with post hoc analyses (Tukey's HSD) showing significant differences between all pairwise comparisons in the order NC>DAT $>$ DLB. There was no main effect of fluency type $(F(2,32)=2.7, \mathrm{p}=0.11)$, but a significant interaction $(F(2,37)=3.8$ $\mathrm{p}=0.03)$. Post hoc repeated measures $t$ tests showed that there was no significant difference in the mean number of words produced for category or letter fluency by normal controls or Patients with DLB. By contrast, the patients with DAT produced a significantly greater number of words in letter than category fluency $(t=2.7, \mathrm{p}=0.02)$.

OTHER NEUROPSYCHOLOGICAL ASSESSMENTS

Table 3 shows the results collected from the three subject groups on the remainder of the neuropsychological assessments. Previous reports of visuoperceptual deficits in DLB were confirmed by the shape detection screening test and fragmented letter assessments from the VOSP battery, where performance by the patients with DLB was significantly worse than both the controls and patients with DAT. Perhaps surprisingly, there were no significant differences disclosed by the object decision subtest, which had been found previously by Calderon et al..$^{13}$ Poor recognition memory for faces and words was identified both for the DAT and DLB groups. A $3 \times 2$ split plot ANOVA disclosed a main effect of group $(F(2,29)=44.6, \mathrm{p}<0.001)$, with post hoc (Tukey's HSD) analyses showing that both patient groups had equivalent, but significantly poorer recognition memory than the control subjects. There was also a significant main effect of modality (memory for faces being better than for words, overall $(F(2,29)=5.4, \mathrm{p}=0.03)$ but the interaction failed to achieve significance $(F(2,29)=2.6, \mathrm{p}=0.09)$. Finally we found a much greater deficit in the patients with DLB than either other group when they were asked to read aloud the items from the NART.

\section{Discussion}

The neuropsychological results collected in this study confirm that semantic impairment is not limited to patients with dementia of Alzheimer's type (DAT) but is also a feature of dementia with Lewy bodies (DLB). Irrespective of whether semantic memory was tapped using measures of comprehension for pictures or words, or production tasks such as naming or category fluency, the patients with DLB performed worse than control subjects and in most cases at an equivalent level to a set of matched patients with DAT. The study also replicated previous findings of a visuoperceptual deficit in $\mathrm{DLB}^{13}$ as well as poor recognition memory for face and word stimuli. ${ }^{17} 28$ These

Table 3 Other neuropsychological results for DLB, DAT, and normal control (NC) groups

\begin{tabular}{|c|c|c|c|c|c|c|}
\hline Test (maximum score) & $N C$ & $D L B$ & $D A T$ & $\begin{array}{l}\text { One way } \\
\text { ANOVA } \\
F \text { Value }\end{array}$ & $p$ Value & $\begin{array}{l}\text { Significant post hoc } \\
\text { differences }{ }^{\star}\end{array}$ \\
\hline Letter fluency (mean number/letter) & $14.9(3.4)$ & $5.7(3.0)$ & $10.5(4.0)$ & See text & & \\
\hline VOSP Shape detection screener test (20) & $19.3(0.9)$ & $17.8(2.3)$ & $19.7(0.5)$ & 5.5 & 0.009 & $\mathrm{NC}=\mathrm{DAT}>\mathrm{DLB}$ \\
\hline VOSP Fragmented letters (20) & $19.3(0.8)$ & $15.0(6.1)$ & $18.6(1.2)$ & 5.2 & 0.01 & $\mathrm{NC}=\mathrm{DAT}>\mathrm{DLB}$ \\
\hline VOSP Object decision (20) & $16.4(2.8)$ & $14.8(2.8)$ & $17.1(2.3)$ & 2.0 & 0.16 & N/A \\
\hline SRMT Faces (25) & $24.4(0.6)$ & $19.1(2.9)$ & $19.6(3.6)$ & See text & & \\
\hline SRMT Words (25) & $24.4(1.2)$ & $18.3(2.8)$ & $17.0(1.9)$ & See text & & \\
\hline NART (50) & $40.9(6.0)$ & $20.0(7.5)$ & $36.6(6.0)$ & 31.7 & $<0.001$ & $\mathrm{NC}=\mathrm{DAT}>\mathrm{DLB}$ \\
\hline
\end{tabular}

Results are reported as mean (SD).

$\star=$ Denotes no significant difference; > denotes significantly higher score.

N/A=Not applicable. 
results add to those summarised in table 1 (see introduction) and emphasise the view that patients with DLB have a generalised dementia that affects many different domains of performance. ${ }^{69}$

Given the evidence for multiple cognitive impairments in DLB, including poor attention, visuoperceptual and executive function, accurate assessment of semantic memory is not straightforward. Many tests of conceptual knowledge rely on picture stimuli and require the subject to problem solve. These extrasemantic processes are true of some of the assessments in this study including the camel and cactus test of associative knowledge, sorting, and fluency tasks. In this vein, it is interesting to note that unlike the patients with DAT, the DLB group showed an equal drop in both category and letter fluency which would be consistent with poor executive skills and working memory. ${ }^{12}$ In the battery of semantic assessments, however, there were three other tasks that do not rely on these extra-semantic processes. Although requiring a decision, spoken word-picture matching is a very straightforward measure of comprehension. The graded naming test and 64 item picture naming require on line access to conceptual knowledge to drive name retrieval and the graded naming test is only a relatively stringent task because the stimuli included are relatively unfamiliar. On all three tests the DLB group exhibited impaired performance.

The only major difference between the two patient groups highlighted by the semantic memory tasks was an effect of the modality of presentation on performance. The patients with DLB were significantly worse at the picture than word version of the camel and cactus test. Patients with a semantic memory impairment either show no modality difference (as found for the DAT group reported here) or relatively better performance for pictured concepts, which results from the fact that an object's structure gives immediate clues to our conceptual knowledge (for example, the type of object, it's use, etc). ${ }^{29}{ }^{30}$ The poor performance of patients with DLB with pictures would be surprising, therefore, if it were not for the fact that they also have visuoperceptual deficits. It seems most likely that the poor picture comprehension of patients with DLB reflects a combination of central semantic impairment and a visuoperceptual deficit.

It is possible that the visuoperceptual deficit in DLB would also explain their relatively poor reading of the words included in the NART and would suggest that the estimate of premorbid IQ normally derived from this estimate would be inaccurate (though we note that previous studies have found equivalent accuracy in DLB and DAT). ${ }^{15} 1631$ The items included in this assessment are both very infrequent and orthographically unusual, possibly making them sensitive to a perceptual deficit. Indeed the most common error type produced by the patients with DLB was an omission rather than the incorrect pronunciations seen in the DAT group.

\section{Conclusion}

The present study found clear evidence for a semantic impairment in both DLB and DAT. This evidence adds to the picture of a generalised dementia seen in both conditions. ${ }^{19}$ The summary of the neuropsychological findings (see table 1) suggests that the disorders are most likely to be correctly differentiated on neuropsychological grounds by the profound attentional and visuoperceptual deficits and, perhaps, the relatively good orientation and delayed recall seen in DLB.

1 McKeith IG. Dementia with Lewy bodies: clinical and pathological diagnosis. Alzheimer's Reports 1998;1:83-7.

2 McKeith IG, Galasko D, Kosaka K, et al. Clinical and pathological diagnosis of dementia with Lewy bodies (DLB). Report of the Consortium on Dementia with Lewy (DLB). Report of the Consortium on Dementia with Lewy Bodies (CD

3 Perry RH, Irving D, Blessed G, et al. Senile dementia of Lewy body type. A clinically and neuropathologically distinct form of Lewy body dementia in the elderly. $\mathcal{f} \mathrm{Neu}$ rol Sci 1990;95:119-39.

4 Hely MA, Reid WGJ, Halliday GM, et al. Diffuse Lewy body disease: clinical features in nine cases without coexistent Alzheimer's disease. F Neurol Neurosurg Psychiatry 1996;60:531-8.

5 McKeith IG, Perry RH, Fairbairn AF, et al. Operational criteria for senile dementia of Lewy body type (SDLT). teria for senile dementia of

6 Hansen L, Salmon D, Galasko, et al. The Lewy body variant of Alzheimer's disease: a clinical and pathologic entity. Neurology 1990;40:1-8.

7 Perry EK. Neurochemical pathology in degenerative dementias. In: Hodges JR, ed. Early onset dementias. Oxford: Oxford University Press (in press).

8 Cercy SP, Bylsma FW. Lewy bodies and progressive dementia: a critical review and meta-analysis. F Int Neuropsychol Soc 1997;3:179-94.

9 Salmon DP, Galasko D, Hansen LA. Dementia with Lewy bodies. In: Hodges JR, ed. Early onset dementias. Oxford: Oxford University Press (in press).

10 Ishii K, Yamaji S, Kitagaki H, et al. Regional cerebral blood flow difference between dementia with Lewy bodies and flow difference between dementia

11 Kosaka K, Iseki E. Dementia with Lewy bodies. Curr Opin Neurol 1996;9:271-5.

12 Salmon D, Galasko D, Hansen L, et al. Neuropsychological deficits associated with diffuse Lewy body disease. Brain Cogn 1996;31:148-65.

13 Calderon J, Perry RJ, Erzinclioglu SW, et al. Perception, attention, and working memory are disproportionately mpaired in dementia with Lewy bodies compared with Alzheimer's disease. F Neurol Neurossurg Psychiatry 2001; 70;157-64.

14 Perry RJ, Hodges JR. Attention and executive deficits in Alzheimer's disease: a critical review. Brain 1999;122:383404 .

15 Sahgal A, Galloway PH, McKeith IG, et al. A comparative study of attentional deficits in senile dementias of Alzheimer and Lewy body types. Dementia 1992;3:350-4.

16 Sahgal A, Galloway PH, McKeith IG, et al. Matching-tosample deficits in patients with senile dementias of the Alzheimer and Lewy body types. Arch Neurol 1992;49: $1043-6$

17 Shimomura T, Mori E, Yamashita H, et al. Cognitive loss in dementia with Lewy bodies and Alzheimer's disease. Arch Neurol 1998;55:1547-52.

18 Connor DJ, Salmon DP, Sandy TJ, et al. Cognitive profiles of autopsy-confirmed Lewy body variant $v$ pure Alzheimer's disease. Arch Neurol 1998;55:994-1000.

19 Salmon DP, Butters N, Chan AS. The deterioration of semantic memory in Alzheimer's disease. Can f Exp Psychol 1999;53:108-16.

20 McKhann G, Drachman D, Folstein M, et al. Clinical diagnosis of Alzheimer's disease. Report of the NINCDSADRDA Word Group under the auspices of the DepartADRDA Word Group under the auspices of the Department of Health and Human Services Task

21 Howell DC. Statistical methods for psychology. Boston, MA: PWS-KENT, 1992.

22 McKenna P, Warrington EK. The graded naming test. Windsor, UK: NFER-Nelson, 1983.

23 Snodgrass JG, Vanderwart M. A standardised set of 260 pictures: norms for name agreement, image agreement, familiarity, and visual complexity. $\mathcal{F}$ Exp Psychol Learn Mem Cogn 1980;6:174-215.

24 Howard D, Patterson K. The pyramids and palm trees test: a test of semantic access from words and pictures. Bury St Edmunds: Thames Valley Test Company, 1992.

25 Warrington EK, James M. The visual object and space perception battery. Bury St Edmunds: Thames Valley Test tion battery. Bury

26 Warrington EK. Short recognition memory test. Hove: Psychology Press, 1996. 
27 Nelson HE. National adult reading test (NART): for the assessment of premorbid intelligence in patients with dementia. ment of premorbid intelligence

28 Walker Z, Allen R, Shergill S, et al. Neuropsychological performance in Lewy body dementia and Alzheimer's disease. Br F Psychiatry 1997;170:156-8.

29 Bozeat S, Lambon Ralph MA, Patterson K, et al. Non-verbal semantic impairment in semantic dementia. Cognitive Neuropsychology 2000;17:437-66.

30 Lambon Ralph MA, Howard D. Gogi aphasia or semantic dementia? Simulating and assessing poor verbal comprehension in a case of progressive fluent aphasia. Neuropsychogia 2000;38:1207-15.
31 Sahgal A, McKeith IG, Galloway PH, et al. Do differences in visuospatial ability between senile dementias of the Alzheimer and Lewy body types reflect differences solely in mnemonic function? f Clin Exp Neuropsychol 1995;17: $35-43$.

32 Galasko D, Katzman R, Salmon DP, et al. Clinical and neuropathological findings in Lewy body dementias. Brain Cogn 1996;31:166-75.

33 Gnanalingham KK, Byrne EJ, Thornton A, et al. Motor and cognitive function in Lewy body dementia: comparison with Alzheimer's and Parkinson's diseases. F Neurol Neurosurg Psychiatry 1997;62:243-52. 